\title{
Volcanic eruptions recorded in an ice core from Collins Ice Cap, King George Island, Antarctica
}

\author{
Han Jiankang, ${ }^{1} \mathrm{X}_{\mathrm{ie}} \mathrm{Zighu}_{\mathrm{i}}{ }^{1}$ Dai Fengnian, ${ }^{2} \mathrm{Z}_{\text {hang }}$ Wanchang ${ }^{3}$ \\ ${ }^{1}$ Hunan Normal University, Changsha, Hunan 410081, China \\ ${ }^{2}$ Desert Research Institute, Chinese Academy of Sciences, Lanzhou, Gansu 730000, China \\ ${ }^{3}$ Lanzhou Institute of Glaciology and Geocryology, Chinese Academy of Sciences, Lanzhou, Gansu 730000, China
}

\begin{abstract}
Careful mineral and structural analyses have revealed the characteristics of volcanic ash in the nine horizons of an $80.2 \mathrm{~m}$ ice core from Collins Ice Cap, King George Island, Antarctica.

Under the assumption of steady state, the Dansgaard-Johnsen flow model was employed to date the core. The volcanic eruptive sequence established for the South Shetland Islands region since AD 1650 shows seven volcanic eruptive cycles during the past 340 years covered by the ice core. It seems that during the period 1875-1925 there was frequent volcanic activity, with perhaps many eruptions at Deception Island. The years 1650-1800 appear to have been a quiet period, followed by a more turbulent century. The past century is basically a tranquil era except for two turbulent epochs at the beginning of the century and in the $1950 \mathrm{~s}-70 \mathrm{~s}$.

Many of the volcanic eruptions in the ice-core sequence are found in the previously reported records for this region. The few that are not in the records should be further investigated. The absence of any 1967-70 eruption trace in the core suggests that this period may represent a minimum in volcanic activity.
\end{abstract}

\section{INTRODUCTION}

An explosive volcanic eruption illustrates the dynamic nature of Earth. Major volcanic eruptions, such as those of Laki in AD 1783 at high latitude $\left(64^{\circ} \mathrm{N}\right)$ and Tambora in AD 1815 near the Equator $\left(8^{\circ} \mathrm{S}\right)$, deposit large amounts of strong acids on a global or hemispheric scale, making it possible to detect volcanic acid horizons in polar ice (Clausen and others, 1988). Ice-core records from both polar regions provide one of the best means available for determining the potential atmospheric impact and global significance of these explosive volcanic eruptions. For example, volcanic events recorded in Greenland ice-core sulfate series correlate with annual changes in atmospheric temperature, exhibiting evidence for sulfate aerosol shielding (Lyons and others, 1990; Stuiver and others, 1995; White and others, 1997) and providing the most reliable means for evaluating past variability within the volcanic-climate system. However, to understand the global volcanic-climate system by means of polar ice-core study, it is essential to identify historic volcanic events in the polar regions, in addition to the major eruptions around the world. It is suggested, first of all, that the eruption sequence for the volcanoes active at present and those having historical eruption records should be reconstructed, even if some of them are only of local significance. Several polar ice cores, for example from Byrd station, West Antarctica (Gow and Williamson, 1971; Kyle and Jezek, 1978), have shown that some historical eruptions were recorded in polar ice in the form of ash layers owing to the relative proximity of the core site to the volcano(es). These ice cores probably contain the most complete record of the history and products of the eruptions.
InWest Antarctica, six zones with active volcanisms since the Pleistocene have been recognized (González-Ferran, 1991). The Bransfield Rift, where the South Shetland Islands (SSI; Fig. 1) are located, experienced the most recent eruptions in 1967, 1969 and 1970 on Deception Island (GonzálezFerran, 1991). Qin and others (1994) reported the discovery, in the ice cores recovered from Nelson Island, of a tephra layer that appears to be from the 1970 Deception Island eruption. Orheim (1972) suggested, based on the measurement of seasonal wind-blown dust layers in the glacial ice at Deception Island, that there was a series of eruptions during the period 1912-17. Among the earliest accounts of volcanic activity on the SSI was Wilkers' (1845) description of the 1842 eruption at Deception Island. Earlier eruptions, including

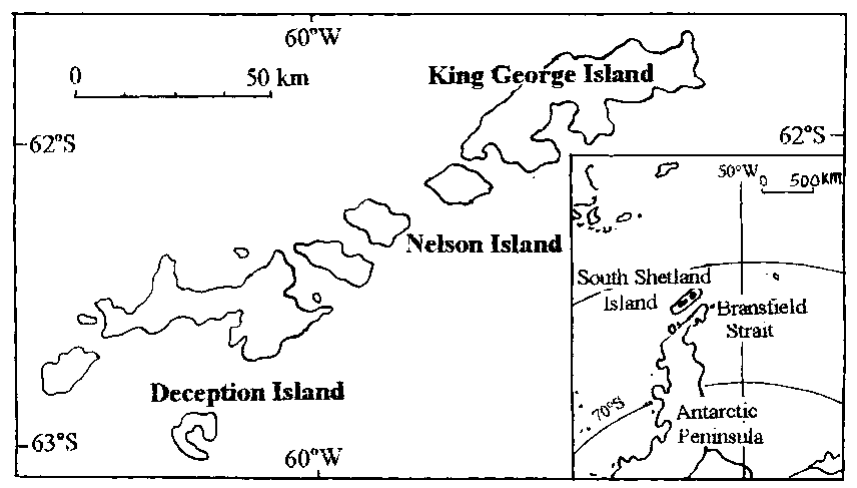

Fig. 1. Map showing the position of King George Island and Deception Island, SSI. 
the events at Deception Island and Penguin Island (near King George Island, SSI), are presented in Simkin and Siebert (1994). But some of these events need to be confirmed or corrected because of their uncertain data origin. For instance, of the ten volcanic events listed above extending back from AD 1956 to 1800, four are questionable for Deception Island, as are two of the Penguin Island eruptions.

King George Island, about $120 \mathrm{~km}$ from the active volcanic Deception Island, is the largest of the SSI that have been volcanically active in historic times (Fig. 1). More than $90 \%$ of King George Island is covered by the Collins Ice Cap. Several ice cores, one of which reached $80.2 \mathrm{~m}$ in depth, were recovered in the 1991-93 field campaign by the Chinese Antarctic Research Expedition (CHINARE) at a dome summit $\left(62^{\circ} 10^{\prime} \mathrm{S}, 58^{\circ} 50^{\prime} \mathrm{W}\right.$; $252 \mathrm{~m}$ a.s.l.). Nine horizons with coarse, dark-brown material were displayed along the $80 \mathrm{~m}$ core. Structural and mineral analysis revealed the characteristics of volcanic ash contained in the horizons. Core-dating given by a modeled time-scale based on the investigation of ice dynamics, mass balance, radar-echo sounding, etc., established the corresponding age of the horizons. Two essential questions will be stressed in our discussion: (1) Could these horizons represent the volcanic eruptive sequence for a certain historic period in the SSI region? (2) What is the relation between the established volcanic sequence and the available historical records?

\section{ICE CORES AND VISIBLE VOLGANIG DEPOSITS}

Collins Ice Cap consists of a few domes up to some $700 \mathrm{~m}$ a.s.l. The 1991-93 fieldwork, including drilling activity, was carried out in a $20 \mathrm{~km}$ long section connecting two domes, High Dome at $702 \mathrm{~m}$ a.s.l. and Low Dome at $252 \mathrm{~m}$ a.s.l., in the western part of the ice cap (Fig. 2). Low Dome is about $3 \mathrm{~km}$ from the Uruguayan research station, Artigas (Fig. 2). A comprehensive glaciological study of mass balance, thermal regime, equilibrium-line altitude (ELA), ice-formation zones, the structure of snow-firn sequences, etc., was conducted along the main divide of the section over a period of more than 1 year (October 1991-January 1993). It was revealed that the ice in the study area is polythermal: temperate on High Dome and cold on Low Dome (Han and others, 1995b). The

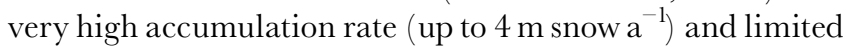
drilling depth (about $50 \mathrm{~m}$, at which depth a water film was encountered) restricted the collection of a long-term cli-

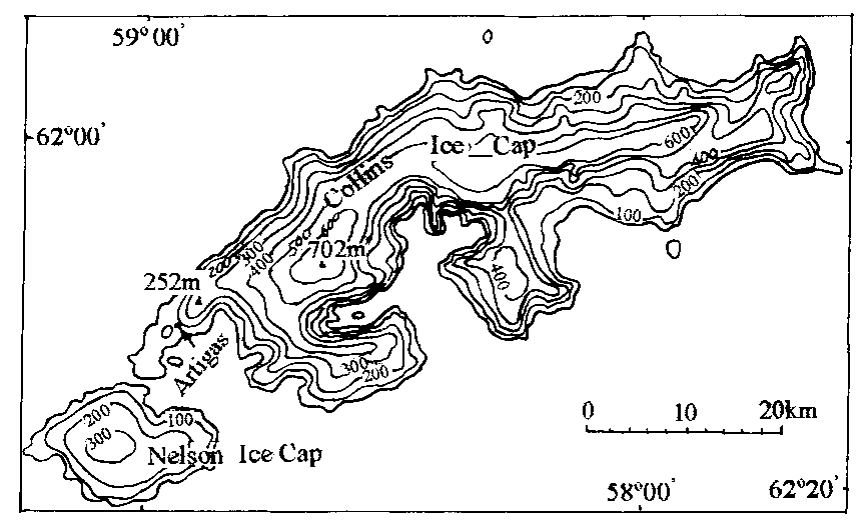

Fig. 2. Map showing the location of work carried out on the Collins Ice Cap and the coring site at the summit of Low Dome. Contours are surface elevation $(\mathrm{m})$. matic-environmental record for High Dome. Low Dome, however, with much less accumulation, favorable physical properties and longer cores, provides an opportunity for longer records.

Low Dome is situated on a subglacial hill with a bowl-like concave top, according to the bedrock topography study by Zhu and others (1994). The summit of the dome shows a smooth surface with an ice thickness of $\sim 120 \mathrm{~m}$. The annual mean air temperature is $5.7^{\circ} \mathrm{C}$, estimated by extrapolating from the long series of meteorological data accumulated at the stations on King George Island (Han and others, 1994). Borehole-temperature measurements below the surface suggest cold ice $\left(0.65^{\circ} \mathrm{C}\right)$ at $50 \mathrm{~m}$ depth and $\left(-1.2^{\circ} \mathrm{C}\right)$ at the bottom of the active layer $(\sim 12-15 \mathrm{~m}$ below the surface; Han and others, 1995b). The horizontal ice movement at the summit of Low Dome is $0.328 \mathrm{~m} \mathrm{a}^{-1}$ (Zhang and Han, 1994). The ELA of the ice cap has been fluctuating in the range 140$160 \mathrm{~m}$ a.s.l. in recent years (Xie and others, 1994), well below the elevation of the dome summit (252 $\mathrm{m}$ a.s.l.). Moreover, the ELA did not rise significantly in 1989, the warmest year in the past century (Han and others, 1995a). This suggests that no loss of historical annual layers has occurred, at least for the past century. The disadvantage of Low Dome as a coring site for climatic-environmental study is its low elevation and consequent surface melting in summer seasons. Our in situ daily meteorological observations on the summit logged air temperatures above $0^{\circ} \mathrm{C}$ for several hours, as well as occasional rainfall. The substantial melting of the surface snow by these mechanisms and the resulting percolation into the snowpack may have caused the migration and relocation of the soluble impurities, probably smoothing the chemical signals recorded in the snow. Thus, long seasonal resolution was not considered available in profiles. However, ice-formation mechanism studies (Han and others, 1994, 1995b; Koerner, 1997; Grumet and others, 1998) suggest that some information other than the seasonal variations might still exist in the core. The critical reason for this preservation is that the cold ice beneath the active layer holds the melting water in the current annual layer so that it is refrozen the following winter. It thus protects annual deposits from deeper percolation and further mixing with the previous snow mass. This mechanism is probably also responsible for the interleaving distribution of firn and ice layers in the upper part of the core due to shortterm alternation of warm and cold weather after the intensive summer melt. It could serve as an indicator of annual layers.

Six ice cores were extracted from a $20 \mathrm{~m} \times 20 \mathrm{~m}$ area on the summit of Low Dome. All cores show similar visible features, the most prominent of which is the common appearance of horizons with brown, dark-brown or lignite-like coarse material along the macroscopic stratigraphy (Fig. 3). The longest core, $80.2 \mathrm{~m}$ long, has nine such horizons where the dispersed or concentrated particles are included (Table 1). The scatter grains sampled in the melt are sized in the range $0.11-0.50 \mathrm{~mm}$, with $0.27 \mathrm{~mm}$ predominant for longaxis measurement. The sharp angular shape of the grains is indicative of the bubble-wall shards and lack of weathering or modification after formation (Dai and others, 1993). Optical examination under a polarizing microscope revealed the characteristic structure of an extrusion, composed of opaque metals dominantly and glass shards secondly. Numerous granular air bubbles and micro-porphyritic crystals in the interior of the grains provide supporting evidence for their volcanic nature. Further evidence of the tephra morphology was found under an electron probe (Fig. 3). Qualitative 


\begin{tabular}{|c|c|c|c|c|c|c|c|c|}
\hline \multirow[t]{2}{*}{ No. } & Depth & $\begin{array}{l}\text { Thick- } \\
\text { ness }\end{array}$ & \multirow{2}{*}{ Visible feature } & \multicolumn{2}{|c|}{ Age } & \multirow{2}{*}{$\begin{array}{l}\text { Eruption cycle } \\
\text { (within } \pm 5 \text { a) }\end{array}$} & \multirow[t]{2}{*}{ Historical record } & \multirow[t]{2}{*}{ Source } \\
\hline & $\mathrm{m}$ & $\mathrm{mm}$ & & $\mathrm{a}$ & $\mathrm{a}$ & & & \\
\hline 1 & 21.29 & 10 & Brown, dispersed particles & 36 & 1955 & II & 1956 & Simkin and Siebert (1994) \\
\hline 2 & 40.39 & 5 & Lignite-like, homogeneous particles & 86 & 1907 & III $($ over 7a) & $1905^{*}(?), 1909(?), 1912$ & Simkin and Siebert (1994) \\
\hline 3 & 44.26 & $>5$ & Lignite-like, homogeneous particles & 98 & 1893 & IV (over 5a) & - & \\
\hline 4 & 45.40 & 50 & Brown, discontinuous slice of scatter particles & 103 & 1888 & & - & \\
\hline 5 & 47.01 & 10 & Dark-brown, discontinuous layer of particles & 109 & 1882 & $\mathrm{~V}$ & - & \\
\hline 6 & 48.12 & 5 & Lignite-like, homogeneous particles & 113 & 1878 & (over 7a) & - & \\
\hline 7 & 48.76 & 5 & Dark-brown, discontinuous layer of particles & 115 & 1876 & & 1871 & Simkin and Siebert (1994) \\
\hline 8 & 56.44 & $>5$ & Dark-brown, homogeneous particles & 150 & 1841 & VI & 1842 & Wilkers (1845); \\
\hline & & & & & & & & Simkin and Siebert (1994) \\
\hline 9 & 60.92 & 5 & Dark-brown, homogeneous particles & 174 & 1817 & VII & 1812 & Simkin and Siebert (1994) \\
\hline
\end{tabular}

*For the eruption at Penguin Island.

analysis using a Model EPM-810Q electron probe determined the elemental composition: $\mathrm{Si}, \mathrm{Ti}, \mathrm{Fe}, \mathrm{Al}, \mathrm{Mn}, \mathrm{Mg}$, $\mathrm{Ca}, \mathrm{K}, \mathrm{O}, \mathrm{Na}$, among which $\mathrm{Si}, \mathrm{Al}, \mathrm{Fe}$ and $\mathrm{Mn}$ show the highest content (Dai and others, 1993). All these well-defined layers are indicative of original deposition.

Besides those nine common horizons, some "dirty" bands are found in several cores. These bands appear cloudy because they contain wind-blown dust particles, but are lighter in color than the horizons. Most of the bands in other cores are cross-correlated to those in the $80.2 \mathrm{~m}$ core for age determination using the prime index layers of volcanic tephra deposit common among the cores. The "dirty" layers spaced more-or-less regularly along the core were taken as references for the calculation of the thinning rate of annual layers. A couple of them at about $11 \mathrm{~m}$ depth could be the indicative signal of known eruptions (e.g. 1970 eruption on Deception Island), but were not treated as such due to their random appearance.

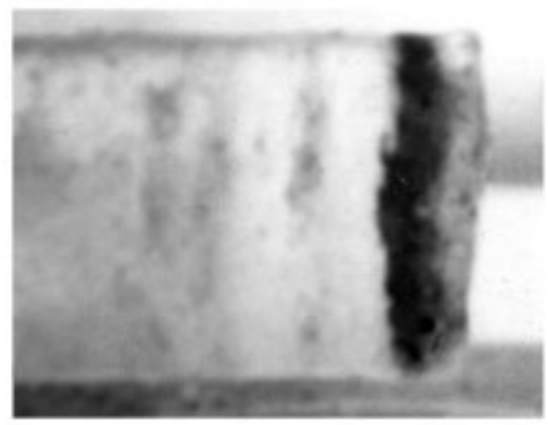

(a)

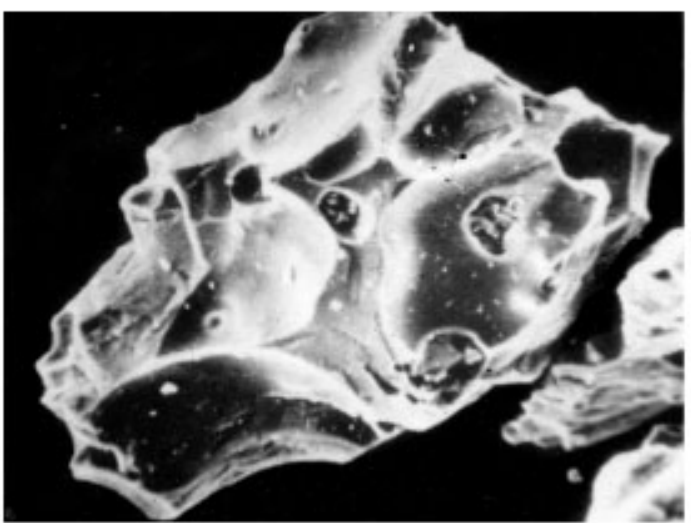

(c)

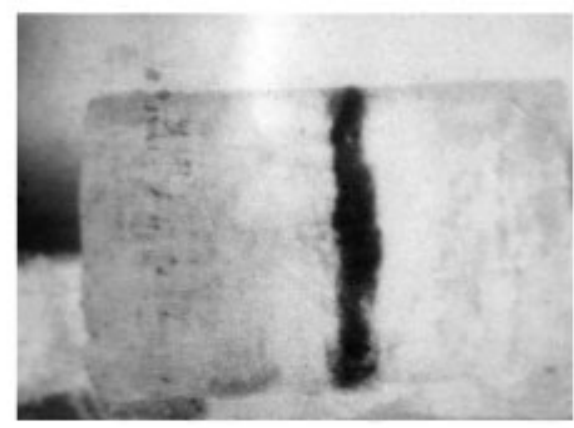

(b)

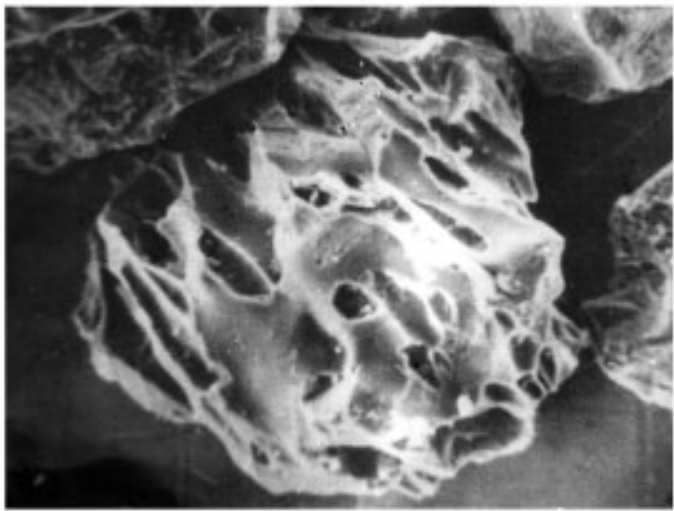

(d)

Fig. 3. A group of photographs showing the visible ash layers in the ice core and the optical microscopic structures. (a,b) Darkbrown volcanic ash layers in the horizons of Collins Ice Cap cores. (c) Double electronic image showing the tattered granular air bubbles and conchoidal fracture on the surface of tephra grains. (d) Double electronic image showing the tattered elliptic air bubbles in the interior of tephra grains. 


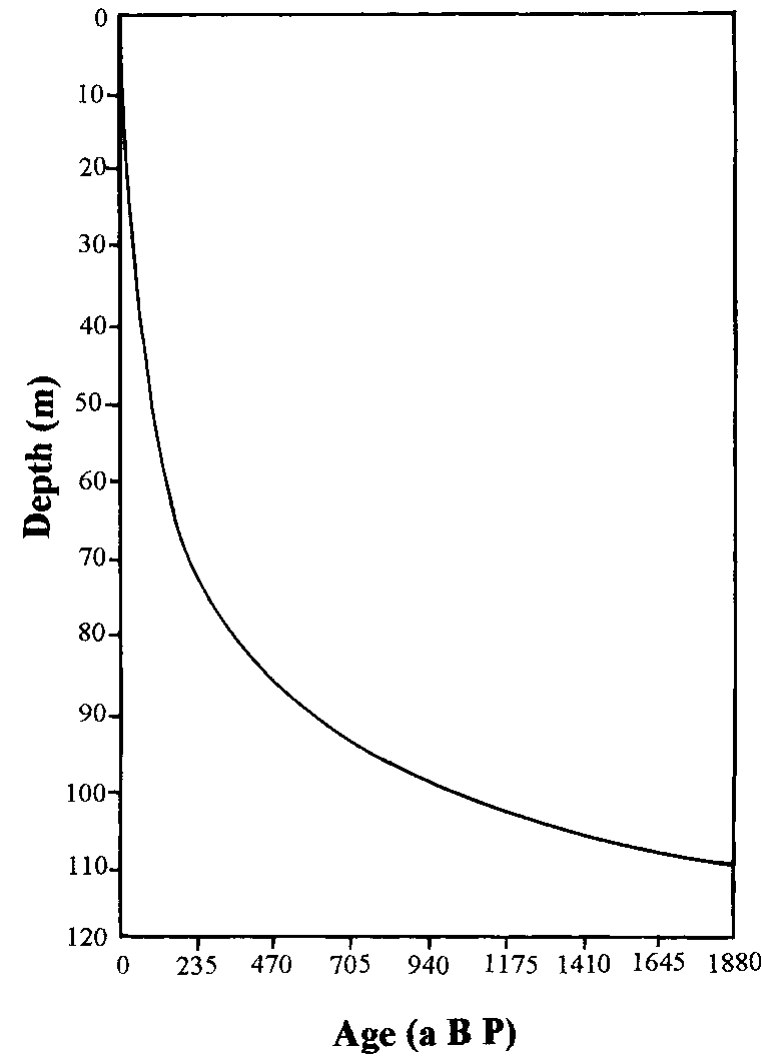

Fig. 4. The time-scale calculated using the Dansgaard-Fohnsen model for the $80.2 \mathrm{~m}$ ice core from Low Dome of Collins Ice Cap.

\section{AGE DETERMINATION}

Various methods for dating cores (e.g. electrical conductivity measurements (Hammer, 1980, 1983), ionic chemistry stratigraphy, the pattern of bomb-produced total $\beta$ activity (Langway and others, 1994) and multi-parameter time series combined with $\delta^{18} \mathrm{O}$ curves) do not work properly on Low Dome owing to the eluviation mechanisms noted above. Thus, we turn to numerical modeling to date the Collins ice cores.

Based on the physical properties of Low Dome, it is reasonable to assume that the dome is in near steady state with a continuous deposition sequence. It is possible that some melting occurs at the base of the dome. But the ice-core dating for this study is limited to the upper part of the core, well above the bed, so a frozen base is also an acceptable assumption.

The age, $T$, at ice-equivalent distance $y$ above the bed at the center of a steady-state ice sheet is (Paterson, 1981)

$$
T=\int_{h}^{y} v^{-1} \mathrm{~d} y
$$

where $h$ is the ice-equivalent thickness and $v$ is the vertical velocity, expressed as the distance an ice particle moves downwards in 1 year, which must be equal to the thickness of one annual layer. Age is calculated from some assumed relation between $v$, or rather the thinning rate $\mathrm{d} v / \mathrm{d} y$ (the horizontal movement could be treated as zero at the drilling site), and $y$.

Considering that the vertical strain rate cannot be uniform with depth if the ice is frozen to the bed, Dansgaard and Johnsen (1969) used a flow model with vertical strain rate constant down to some distance $h^{\prime}$ above the bed and decreasing linearly from there to zero at the bed. This model was adopted in our study.
Equation (1), which is the basis for these time-scales, is true only where there is no horizontal ice movement, i.e. at an ice divide. As stated above, the ice at the summit of Low Dome moves very slowly, indicative of its position very close to the ice divide. As the ice thickness, annual accumulation rate and therefore the vertical velocity, $v$, do not vary greatly in the drilling area (Wen and others, 1994; Zhu and others, 1994), the subsequent equations of the model illustrated by Dansgaard and Johnsen (1969) are valid. The position of $h^{\prime}$ was determined by the varying thickness of annual layers along the core. As shown by the visible stratigraphy (Han and others, 1994) the annual layer thickness at Low Dome summit is approximately $0.7 \mathrm{~m}$ (ice) at $\sim 2.5 \mathrm{~m}$ depth. The annual layer is reduced to some $0.4 \mathrm{~m}$ (ice) at $\sim 28 \mathrm{~m}$ depth, as indicated by the mean interval between two neighboring "dirty" layers. Thus the calculated thinning rate of the annual layer is $\mathrm{d} v / \mathrm{d} y \approx 0.011$, and $h^{\prime}=$ $113 \mathrm{~m}$ when the accumulation rate, $c=0.7 \mathrm{~m} \mathrm{a}^{-1}$, and the ice thickness, $h=120 \mathrm{~m}$, at the summit are accounted for. The time-scale calculated by this model is plotted in Figure 4. A similar time-scale was constructed earlier by using the well-known ice-flow law (Zhang and Han, 1994).

\section{ESTABLISHMENT OF VOLGANIC ERUPTION SEQUENGES}

With the calculated time-scale, two key time limits are first determined. The ice $10 \mathrm{~m}$ above the bedrock of Low Dome is aged 1897 a BP. The bottom of the long core at $80.2 \mathrm{~m}$ corresponds to an age of $360 \mathrm{a} \mathrm{BP}$. The former implies that the reliable records from this subantarctic ice cap go back to some $2 \mathrm{ka} \mathrm{BP}$, and the latter indicates that the extracted $80.2 \mathrm{~m}$ ice core contains about 340 years.

The ages for the volcanic ash horizons are listed in Table 1. Taking into account the maximum difference between the calculated age and the nearest historical record (e.g. Simkin and Siebert, 1994), \pm 5 years was allowed for dating error. This suggests that the most recent volcanic eruption recorded by our core is that in 1956 at Deception Island. Our dating of the horizon at $40.4 \mathrm{~m}$ suggests eruption(s) around 1907, close to that at Deception Island (1912 or 1905?) or to that at Penguin Island (1905?). The most frequent eruptions recorded in our core were concentrated in the fourth quarter of the 19th century. However, four of five horizons in that period have not been reported previously. The 1842 eruption as described by Wilkers (1845) left a distinct trace in our core, with only a lyear difference in the dating. The earliest record provided by the Low Dome core was in 1817, when an eruption occurred at Deception Island (Simkin and Siebert, 1994). Thus, several recorded eruptive activities at Deception Island, as compiled by Simkin and Siebert (1994), are found in our cores, but not the most recent (1967-70) or the earliest (1800).

The absence of ash layers corresponding to the eruptions in 1967-70 at Deception Island poses a significant question for the calculated time series. An attempt was made to construct another series by taking the tephra horizon at $21.3 \mathrm{~m}$ as the index of the 1970 eruption. However, in the new series most other volcanic horizons do not match with any recorded eruptions within a range of 10 years. So it appears that this alternative series is unacceptable. As mentioned above, we found a couple of dirty bands at about $11 \mathrm{~m}$ depth. These could be the indicative signal of the 1967-70 events 
according to our modeled time-scale. Actually, in some of the Nelson ice cores (Qin and others, 1994) the 1967-70 eruptions were exhibited as scattered particles, too. The fact that the 1967-70 eruptions are not recorded as dark horizons in Low Dome cores suggests that the original eruptive ash did not reach the drilling site, even though the drilling site was within $10 \mathrm{~mm}$ of the tephra isopach produced by the 1970 eruption (González-Ferran, 1991). This also seems contrary to Qin and others' (1994) observation in the Nelson Island ice core. This discrepancy may be explained by the 8 $10 \mathrm{~km}$ distance between the two sites. Another possible explanation is that Low Dome is located slightly off the track of the predominant (east-northeastward, i.e. clockwise over Antarctica) wind direction. The above may explain the appearance of dirty bands rather than ash layers for the 1967-70 eruptions in Low Dome cores.

A single volcanic eruption usually lasts a very short time, but the dynamic subduction process causing volcanic eruptions often lasts for a few years. For instance, the 1967-70 eruptions at Deception Island are actually three phases of one eruptive cycle (González-Ferran, 1991). With this in mind, we grouped the eruptions recorded in the Collins Ice Cap core into cycles of 5 years, i.e. the eruption series within a 5 year time interval are brought into one group as a cycle. Including the 1967-70 cycle, the 340 year history covered by our core contains seven eruptive cycles (Table 1). The longest (a combination of two successive cycles) lasts for 7 years. Because of the possible absence of a full cycle, the seven cycles should be regarded as the minimum for the past 340 years. These eruptive cycles outline the general history of volcanic activity in the SSI region. The events falling into cycles IV and V, most of which have not been reported previously, should be specially investigated, perhaps utilizing ice cores from other glaciers in the SSI region.

\section{CONGLUSIONS}

Nine volcanic ash horizons are found in an $80.2 \mathrm{~m}$ ice core from Collins Ice Cap. The volcanic origin of these horizons is confirmed by mineral and chemical analyses.

Assuming the ice cap is in steady state, the DansgaardJohnsen flow model was constructed to date the core. A time series of volcanic eruptions in the SSI region since AD 1650 was thus established. Seven volcanic eruption cycles can be distinguished during the past 340 years. During the period 1875-1925, there seem to have been frequent volcanic eruptions, many perhaps on Deception Island. The period 16501800 appears to be quiet. This was followed by a century of higher volcanic activity. The past century has been a volcanically tranquil era except for a few turbulent periods at the beginning of the century and during the $1950 \mathrm{~s}-70 \mathrm{~s}$.

Most of the recorded eruptions at Deception Island, as compiled in Simkin and Siebert (1994), have been found in the Collins Ice Cap core. A few horizons do not correspond with any eruptions in the compiled list, These may be previously undiscovered or unreported eruptions in the region. The absence of a distinct horizon for the most recent volcanic events in the period 1967-70 suggests that the volcanic eruptions found in this study may represent a minimum in the eruptive history.

\section{REFERENCES}

Clausen, H. B. and C. U. Hammer. 1988. The Laki and Tambora eruptions as revealed in Greenland ice cores from 11 locations. Ann. Glaciol., 10, 16-22.

Dai, F. and 6 others. 1993. [The first verification of volcano extrusive in an ice core from Low Dome of Collins Ice Cap, King George Island, Antarctica.] Antarct. Res. (Chinese), 5(3), 75-77. [In Chinese with English summary.]

Dansgaard, W. and S. J. Johnsen. 1969. A flow model and a time scale for the ice core from Camp Century, Greenland. 7. Glaciol., 8(53), 215-223.

González-Ferran, O. 1991. Antarctic volcanic hazard. Korean 7. Polar Res., 2(1), Special Issue, 97-105.

Gow, A. J. and T. Williamson. 1971. Volcanic ash in the Antarctic ice sheet and its possible climatic implications. Earth Planet. Sci. Lett., 13(1), 210-218.

Grumet, N. S., C. P. Wake, G. A. Zielinski, D. Fisher, R. Koerner and J. D. Jacobs. 1998. Preservation of glaciochemical time series in snow and ice from the Penny Ice Cap, Baffin Island. Geophys. Res. Lett., 25(3), 357-360.

Hammer, C. U. 1980. Acidity of polar ice cores in relation to absolute dating, past volcanism, and radio-echoes. f. Glaciol., 25(93), 359-372.

Hammer, C. U. 1983. Initial direct current in the buildup of space charges and the acidity of ice cores. 7. Phys. Chem., 87(21), 4099-4103.

Han Jiankang, Kang Jiancheng, Wen Jiahong, A. Lluberas and F. Rodriguez. 1994. General characteristics in stratigraphy and density for ice cores from Collins Ice Cap, King George Island, Antarctica. Antarct. Res., 6(1), 40-46.

Han Jiankang, Xu Chenhai and Kang Jiancheng. 1995a. [Change trends of the mean annual air temperature in the last century in the South Shetland Islands, Antarctica.] 7. Glaciol. Geocryol., 17(3), 268-273. [In Chinese with English summary.]

Han Jiankang, Jin Huijun, Wen Jiahong and Shang Xinchun. 1995b. Temperature distribution of Collins Ice Cap, King George Island, Antarctica. Antarct. Res., 6(2), 57-65.

Koerner, R. M. 1997. Some comments on climatic reconstructions from ice cores drilled in areas of high melt. f. Glaciol., 43(143), 90-97; Erratum $43(144), 375-376$.

Kyle, P. R. and P. A. Jezek. 1978. Compositions of three tephra layers from the Byrd Station ice core, Antarctica. 7. Volcanol. Geotherm. Res., 4, 225-232.

Langway, C. C., Jr, K. Osada, H. B. Clausen, C. U. Hammer, H. Shoji and A. Mitani. 1994. New chemical stratigraphy over the last millennium for Byrd Station, Antarctica. Tellus, 46B (1), 40-51.

Lyons, W. B., P. A. Mayewski, M. J. Spencer, M. S. Twickler and T. E. Graedel. 1990. A Northern Hemisphere volcanic chemistry record (1869-1984) and climatic implications using a south Greenland ice core. Ann. Glaciol., 14, 176-182.

Orheim, O. 1972. A 200-year record of glacier mass balance at Deception Island, southwest Atlantic Ocean, and its bearing on models of global climatic change. Ohio State Univ. Inst. Polar Stud. Rep. 42.

Paterson, W. S. B. 1981. The physics of glaciers. Second edition. Oxford, etc., Pergamon Press.

Qin Dahe, G. A. Zielinski and M. S. Germani. 1994. Volcanic ash in the cores of Nelson Ice Cap, Antarctica and the glacier mass balance. Chin. Sci. Bull., 24(7), 779-784.

Simkin, T. and L. Siebert. 1994. Volcanoes of the world. Second edition. Tucson, AZ, Geoscience Press.

Stuiver, M., P. M. Grootes and T. F. Braziunas. 1995. The GISP2 $\delta^{18} \mathrm{O}$ climate record of the past 16,500 years and the role of the Sun, ocean and volcanoes. Quat. Res., 44(3), 341-354.

Wen Jiahong and 6 others. 1994. [A preliminary analysis of mass balance characteristics on small dome of Collins Ice Cap, King George Island, Antarctica.] Antarct. Res. (Chinese), 6(1), 47-57. [In Chinese with English summary.]

White, D. E., J.W. C. White, E. J. Steig and L. K. Barlow. 1997. Reconstructing annual and seasonal climatic responses from volcanic events since A.D. 1270 as recorded in the deuterium signal from the GISP2 ice core. F. Geophys. Res., 102, 19,683-19,694.

Wilkers, C. 1845. American exploring expedition. Narrative of the United Exploring Expedition during the year 1838-1842.Vol. 1-V, with an atlas. Philadelphia, PA, Lea and Blanchard.

Xie Zichu, Wen Jiahong and Han Jiankang. 1994. [Calculation of multi-year mass balance variations on small dome of Collins Ice Cap, King George Island.] Antarct. Res. (Chinese), 6(2), 32-39. [In Chinese with English summary.]

Zhang Wanchang and Han Jiankang. 1994. [A preliminary age determination with numerical modelling for an ice core extracted from Low Dome of Collins Ice Cap, King George Island, Antarctica.] Antarct. Res. (Chinese), 6(3), 25-32. [In Chinese with English summary.]

Zhu Guocai, Jing Xiaoping, Han Jiankang, Gao Xinsheng, Kang Jiancheng and Wen Jiahong. 1994. [Radar sounding and study of the bedrock topography on Collins Ice Cap.] Antarct. Res. (Chinese), 6(2), 40-45. [In Chinese with English summary.] 